This item is the archived peer-reviewed author-version of:

\title{
Assessing in-vitro estrogenic effects of currently-used flame retardants
}

\section{Reference:}

Krivoshiev Boris V., Dardenne Freddy, Covaci Adrian, Blust Ronny, Husson Steven.- Assessing in-vitro estrogenic effects of currently-used flame retardants

Toxicology in vitro - ISSN 0887-2333 - 33(2016), p. 153-162

Full text (Publisher's DOI): http://dx.doi.org/doi:10.1016/J.TIV.2016.03.006

To cite this reference: http://hdl.handle.net/10067/1358930151162165141 


\section{Accepted Manuscript}

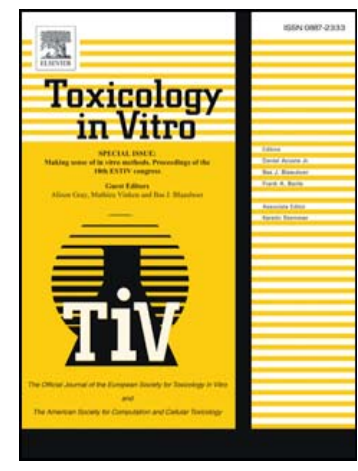

PII:

S0887-2333(16)30044-3

doi: 10.1016/j.tiv.2016.03.006

Reference: $\quad$ TIV 3744

To appear in:

Received date: 5 October 2015

Revised date: $\quad 7$ March 2016

Accepted date: $\quad 11$ March 2016

Please cite this article as: Krivoshiev, Boris V., Dardenne, Freddy, Covaci, Adrian, Blust, Ronny, Husson, Steven J., Assessing in-vitro estrogenic effects of currently-used flame retardants, (2016), doi: 10.1016/j.tiv.2016.03.006

This is a PDF file of an unedited manuscript that has been accepted for publication. As a service to our customers we are providing this early version of the manuscript. The manuscript will undergo copyediting, typesetting, and review of the resulting proof before it is published in its final form. Please note that during the production process errors may be discovered which could affect the content, and all legal disclaimers that apply to the journal pertain. 


\section{Assessing in-vitro estrogenic effects of currently-used flame}

\section{retardants}

Boris V. Krivoshiev ${ }^{a}$, Freddy Dardenne ${ }^{a}$, Adrian Covaci ${ }^{b}$, Ronny Blust ${ }^{a}$, Steven J. Husson ${ }^{a}$

${ }^{\text {a }}$ Department of Biology, Systemic Physiological \& Ecotoxicological Research, University of Antwerp,

Antwerp, Belgium

${ }^{b}$ Department of Pharmaceutical Science, Toxicological Centre, University of Antwerp, Antwerp,

Belgium

*Corresponding author:

E-mail: boris.krivochiev@uantwerpen.be

Telephone: +3232653501

Fax: +3232653497 


\section{Abstract}

Flame retardants are chemicals that are added to nearly all manufactured materials. Additionally, there has been a steady increase in diseases resulting from endocrine-disruption with an aligned increase in use of chemicals. Given the persistence, potential bioaccumulation, limited toxicological understanding, and vast use of flame retardants, there is a need to investigate potential endocrinedisruptive activity associated with these compounds in an effort for better risk assessment. We therefore used the MCF-7 flow-cytometric proliferation assay in an effort to establish potential estrogen-disrupting effects of twelve currently-used flame retardants. Triphenyl phosphate, tris (1,3dichloro-2-propyl) phosphate, tris (butyl) phosphate, hexabromocyclododecane, and tetrabromobisphenol A showed statistically significant estrogenic activity, with hexabromocyclododecane being the most potent of the five $\left(\mathrm{EC}_{20}\right.$ of $\left.5.5 \mu \mathrm{M}\right)$. Tris(2-butoxyethyl) phosphate, tris (1,3-dichloro-2-propyl) phosphate, tri (2-chloroethyl) phosphate, tris (butyl) phosphate, hexabromocyclododecane, tetrabromobisphenol A, and tris (2,3,-dibromopropyl) isocyanurate harboured anti-estrogenic activity when co-treating with $17 \beta$-estradiol, with hexabromocyclododecane showing the highest potency $\left(\mathrm{IC}_{20}\right.$ of $\left.17.6 \mu \mathrm{M}\right)$. Interestingly, some compounds showed both estrogenic and anti-estrogenic effects, indicating both receptor-dependant and -independent mechanisms attributed to some of these compounds, in line with other studies. Multiple currently-used flame retardants may therefore act as xenoestrogens and anti-estrogens, or alter estrogen homeostasis, which could affect endocrine function.

Keywords MCF-7, Flame retardants, Estrogenicity, Endocrine disruption 


\section{Introduction}

Several chemicals found in the environment have been shown to alter endocrine function in animals and humans. Over the past few decades, there has been an increase in endocrine-related diseases and disorders, accompanied by an increase of hormonally active synthetic chemicals in the environment. This has led some to postulate that such adverse health outcomes in both humans and wildlife are the result of exposure to the ever-changing and increasingly complex mixture of hormonally-active chemicals (Bergman et al., 2013; Maffini et al., 2006; Sharpe and Skakkebæk, 1993; Sumpter, 1995). Such adverse effects range from effects on reproduction, foetal development, metabolism, and other vital processes (reviewed in Diamanti-Kandarakis et al., 2009). Additionally, recent attention to the potential effects environmental chemicals may pose to reproductive and developmental health has also been propelled by studies reporting a decrease in semen quality and testosterone levels, with increased incidence of developmental abnormalities of the reproductive tract, and of testicular cancer (reviewed in Sharpe \& Irvine, 2004). Not only were these trends temporal, but also geographically-dependent, providing evidence that such effects were a result of environmental factors.

One manner whereby a chemical may affect endocrine function is by mimicking estrogen itself, or by inducing estrogen-like effects in an indirect way; i.e., increasing estrogen/estrogen receptor expression, thereby sensitising estrogen signalling. For instance, male frogs' eggs exposed to environmentally relevant levels of the pesticide atrazine, developed ovaries and were infertile (Hayes et al., 2002), while also impeding porcine oocyte maturation (Casas et al., 2010), and accelerating the acrosomal reaction in boar sperm (Maravilla-Galvan et al., 2009), highlighting the effects of atrazine on reproductive health. Atrazine was shown to be a CYP19A1 inducer (Roberge et al., 2004), the key enzyme that converts testosterone to estradiol. Additionally, there is evidence that adverse health effects may be carried over to the offspring with one study showing that children born to women that were exposed to several endocrine disruptors developed skin 
abnormalities, (Guo et al., 1999). Accordingly, there is also evidence for the enhancement of deleterious effects based on time of exposure. For instance, animals exposed in utero to bisphenol A have shown higher sensitivity to estradiol (Muñoz-de-Toro et al., 2005), indicating that prenatal exposure to bisphenol A may accentuate possible deleterious effects due to its estrogenicity in later years.

A recent report was published in 2012 by the World Health Organisation (WHO) titled "State of the Science of Endocrine Disrupting Chemicals - 2012". It highlighted the concern that endocrine-related disease and disorders are on the rise, while chemicals with endocrine-disrupting potential were linked to disease outcomes in a laboratory setting. Given the presence of thousands of chemicals being used and introduced into the environment, the WHO highlighted the need to establish insights into potential endocrine-disruptive effects of such chemicals using high-throughput in vitro assays. Such insights could prove valuable in improving risk assessment given the ubiquitous presence of chemicals and the link between endocrine disruption and disease, while limiting the use of laboratory animals.

One particular family of chemicals produced in high volumes are flame retardants (FRs). FRs are compounds that are designed with the primary purpose to prevent the initiation and spread of fire, with several retardants also serving as plasticisers (Meeker and Stapleton, 2010). Due to the need for safer consumer products, FRs are found in nearly all manufactured items, indicating the diverse roles and therefore the highly prevalent use of FRs. Some of these compounds have been shown to migrate out of these materials, thereby contaminating surrounding environments (Covaci et al., 2006; de Wit et al., 2010), distant environments (de Wit et al., 2010), and biota (Covaci et al., 2011). Unsurprisingly, many compounds have been detected in household dust (Abdallah and Harrad, 2009; Ali et al., 2011; Dodson et al., 2012; Harrad et al., 2010). Given the ability for these compounds to undergo long-range atmospheric transport and their high level of persistence (de Wit et al., 2010), exposure to these FRs is not limited solely to humans, and are likely to pose a significant risk to the 
environment. Worryingly, given their persistence and hydrophobicity, bioaccumulation of FRs is also likely. Of note, traces of FRs were detected in human mother's milk (Abdallah and Harrad, 2011; Lignell et al., 2009). It is clear that FRs pose a significant risk to the environment, given their persistence, hydrophobicity, bioaccumulation effects and adverse toxicological effects.

Several FRs have been shown to cause adverse health effects. For example, tris (2,3-dibromopropyl) phosphate, was used in childrens' sleepwear, and its metabolite, 2,3-dibromopropanol, was shown to be highly mutagenic (Blum et al., 1978). Since then, tris (2,3-dibromopropyl) phosphate has been banned from further use. As recently as 2013, hexabromocyclododecane (HBCD) was initially considered safe for use by means of animal testing primarily monitoring for acute effects, but is now selected to be phased out of use by 2015 after decades of use, due to its persistence (de Wit et al., 2010), bioaccumulation (Law et al., 2008), and chronic toxicity (Ema et al., 2008). New regulations are therefore being introduced forcing the FR industry to be in constant flux, with new compounds and/or mixtures being frequently introduced. Brominated flame retardants (BFRs) were initially the compounds of choice due to their low cost and high performance (Birnbaum and Staskal, 2004). However, their persistence, bioaccumulation, and toxicity urged the industries to explore alternatives. So-called novel brominated flame retardants (NBFRs), which are structurally similar to their toxic predecessors, organophosphate flame retardants (PFRs), and metal hydroxides, are currently used (van der Veen and de Boer, 2012). Toxicity testing for these compounds includes several endpoints, such as measuring acute toxicity by monitoring median lethal dose values, skin sensitization, carcinogenic potential, and immuno-, reproductive, and genotoxicity. Unfortunately, however, little insights into the compounds' effects on estrogen function are available to date.

In this study, we adopted a flow-cytometric proliferation assay using the human breast carcinoma cell line (MCF-7) to gain further understanding into potential (anti)estrogenic effects of twelve FRs, of which eleven are currently used as evidenced by detection in house dust or environment (Dodson et al., 2012; Zhu et al., 2012). The compound 9,10-dihydro-9-oxa-10-phosphaphenanthrene (DOPO) 
was also included since it is earmarked to replace many FRs given its lack of acute and chronic toxicity (Waaijers et al., 2013). Additionally, the absence of DOPO in house dust samples may be attributed to the fact that DOPO is used as a reactive FR which is embedded into the polymer, thereby limiting the amount of compound that is able to diffuse out of products and into surrounding environments (Salmeia and Gaan, 2015). Proliferation of the estrogen receptor $\alpha$ positive human breast cancer cell line, MCF-7, has been routinely used as a measure of estrogenicity (Dorosh et al., 2010; Korner et al., 1998; Olsen et al., 2003; Preuss et al., 2006; Soto et al., 1995; Zhang et al., 2014). This allows rapid screening of compounds for potential estrogenic effects, as previously demonstrated when screening pure compounds and environmental samples (Vanparys et al., 2010). The assay has been compared to the performance of other in vitro estrogen assays present in the literature retrospectively. It has been found to correlate well both qualitatively and quantitatively to the classical E-screen $\left(R^{2}=0.98\right)$, the estrogen receptor-binding assay $\left(R^{2}=0.84\right)$, and the estrogen receptor-activation assay $\left(R^{2}=0.87\right)$, while also maintaining a coefficient of variation comparable to other estrogen receptor-activation assay (Vanparys et al., 2010). 


\section{Materials and Methods}

\subsection{Chemicals}

Two classes of FRs, PFRs and BFRs, were tested. All compounds except DOPO, HBCD, and TBPH were acquired from Sigma-Aldrich (USA). TBPH and DOPO were obtained from Santa-Cruz Biotechnologies (USA), and Tokyo Chemical Industry (JAP), respectively, while a technical mixture of HBCD which includes all diastereomers of HBCD, was purchased from Acros Organics (UK). 1M stock solutions in 100\% DMSO (Thermo-Fischer Scientific, USA) were prepared for TPP, TBEP, TCEP, TnBP, TEP, DOPO, and TBBPA. Remaining FRs were made in 0.1M stock solutions in 100\% DMSO. The highest concentration tested for each compound is indicated in Table 1 bellow.

\subsection{Cell Culture}

The human breast adenocarcinoma cell line, MCF-7 (ECACC No. 86012803), was maintained as a monolayer in T-75 Nunc culture flasks in Dulbecco's Minimum Essential Medium (DMEM) with phenol red as $\mathrm{pH}$ indicator, supplemented with $1 \mathrm{mM}$ sodium pyruvate, $4 \mathrm{mM}$ L-glutamine, $1 \%$ nonessential amino acids, $50 \mathrm{IU} / \mathrm{ml}$ penicillin, $50 \mathrm{mg} / \mathrm{ml}$ streptomycin, and $5 \%$ heat-inactivated foetal bovine serum (FBS). Cells were cultured in a $37^{\circ} \mathrm{C}$ incubator under $5 \% \mathrm{CO}_{2}$. Cells at $70-80 \%$ confluence were passaged using $0.25 \%$ trypsin/ethylenediaminetetraacetic acid (EDTA) for 1 min at room temperature, followed by the subsequent removal of trypsin and incubation at $37^{\circ} \mathrm{C}$ for 5 min. Cells were split $1 / 8$, with a maximum of 25 passages. Cells were routinely assessed for mycoplasma contamination using the LookOut ${ }^{\circledR}$ Mycoplasma PCR Detection Kit (Sigma-Aldrich, USA) as per manufacturer's instructions. 


\subsection{Treatments}

Treatments were conducted under low-steroid conditions achieved by supplementing phenol redfree DMEM as above but with charcoal dextran-treated foetal bovine serum (CDFBS) (exposure medium) in accordance with previous studies involving this assay (Vanparys et al., 2006, 2010). This served to minimise the possible estrogenic activity of serum and synchronise cells in the $G_{0} / G_{1}$ phase of the cell cycle. After cell attachment in standard growth medium for $24 \mathrm{hrs}$, cells were washed with phosphate buffered saline (PBS with $\mathrm{Ca}^{2+}$ and $\mathrm{Mg}^{2+}$ ) to remove all estrogenic proteins that may be present in FBS and medium was replaced with exposure medium. After 48 hrs exposure which resulted in $G_{0} / G_{1}$ phase synchronisation, exposure medium was refreshed and FR compounds added at concentrations indicated in Table 1 and allowed to expose for 24hrs. Final DMSO concentrations in treatments did not exceed $0.1 \%$. Treatments were done in 2:1 serial dilutions and in triplicate.

\subsection{Compound precipitation}

Precipitation of compounds was assessed by using turbidity as a quantitative measure, as described previously (Petruševska et al., 2013; Wu et al., 2005). Briefly, this entailed solubilising a range of concentrations of compound in $0.1 \%$ DMSO, and pipetting $100 \mu \mathrm{l}$ in a 96-well plate in triplicate. The plate was then incubated for $5 \mathrm{~min}$ at $37^{\circ} \mathrm{C}$ and absorbance measured at $500 \mathrm{~nm}$. Absorbance was directly related to level of precipitation.

\subsection{Cytotoxicity}

Appropriate concentrations with limited or no cytotoxicity were determined by means of a resazurin cell-viability assay. Briefly, 10,000 MCF-7 cells were seeded in 96-well plates and allowed to attach for $24 \mathrm{hrs}$. Medium was then changed to exposure medium, and allowed to culture for $48 \mathrm{hrs}$ at $37^{\circ} \mathrm{C}$ (this mimicked the cell-cycle synchronisation process). Cells were then treated with compound (2:1 serial dilution). Following $24 \mathrm{hrs}$ treatment (the same duration of treatment the cells used for the flow-cytometry proliferation assay), cells were washed with PBS $\left(\mathrm{Ca}^{2+}\right.$ and $\left.\mathrm{Mg}^{2+}\right)$ and $50 \mathrm{mM}$ (made 
up in PBS) resazurin sodium salt (Sigma-Aldrich, USA) was added per well. Cells were allowed to incubate at $37^{\circ} \mathrm{C}$ for $45 \mathrm{~min}$ and fluorescence at $570 \mathrm{~nm}$ was measured. Cytotoxicity was determined by means of statistical significance between highest concentration of FR versus DMSO control using the unpaired t-test.

\subsection{Flow cytometric cell (anti)proliferation assay}

The MCF-7 flow cytometry cell proliferation assay has been described previously (Vanparys et al., 2006). Briefly, 50,000 cells were seeded into 6-well plates and allowed to attach. Following cell-cycle synchronisation in exposure medium for $48 \mathrm{hrs,} \mathrm{compounds} \mathrm{were} \mathrm{added} \mathrm{and} \mathrm{cells} \mathrm{treated} \mathrm{for} 24 \mathrm{hrs}$. Depending on endpoint measured (anti-estrogenicity or estrogenicity) cells were either co-treated with or without $17 \beta$-estradiol (E2) (100 pM). After exposure, cells were harvested by means of trypsinisation and transferred into a 96-well MASTERBLOCK ${ }^{\circledR}$ (Greiner Bio-One GmbH, AUT), followed by two washes with PBS $\left(\mathrm{Ca}^{2+}\right.$ and $\left.\mathrm{Mg}^{2+}\right)$ with intermittent centrifugation at $1500 \mathrm{~g}$ for 5 min at room temperature. Cell pellets were stained with $1 \mathrm{ml}$ freshly-made propidium iodide (PI) staining solution $(0.1 \%$ Triton $\mathrm{X}-100,0.1 \%$ sodium citrate, $50 \mu \mathrm{g} / \mathrm{ml} \mathrm{PI}$, and $10 \mu \mathrm{g} / \mathrm{ml}$ RNase A in PBS $\left(\mathrm{Ca}^{2+}\right.$ and $\left.\left.\mathrm{Mg}^{2+}\right)\right)$. Cells were stored at $4^{\circ} \mathrm{C}$ for $2 \mathrm{hrs}$ prior to flow cytometric analysis.

Flow cytometric measurements were performed using the LSR II Flow Cytometer (BD Biosciences, USA), equipped with a $15 \mathrm{~mW}$ solid state argon-ion laser emitting at $488 \mathrm{~nm}$. PI fluorescence was collected with a 575/25 nm band pass filter after linear amplification. For each measurement, data from 10,000 cells was collected while cell doublets and aggregates were gated out using a twoparameter histogram of FL2-area versus FL2-width. Cell cycle histograms were analysed using ModFit LT 4.1 software packages (Verity Software House Inc., USA). Only cell cycle profiles with a low variation coefficient of the $G_{0} / G_{1}$ peak and low Reduced Chi-Squared (RCS) values were used. Such parameters indicated how well the model described the observed data. The proliferative potential of a FR compound was indicated by the number of cells in the DNA synthesis stage of the cell cycle, the S-phase. Results are presented as the mean value of three independent experiments. 
Given that charcoal-stripping FBS may also lead to the loss of other macromolecules other than estradiol that may affect proliferation (Cao et al., 2009), relative proliferative effect (RPE) of a compound was normalised to the percentage of cells in S-phase in solvent control. This ensured that the baseline proliferation/state of cells that may vary due to varying amounts of macromolecules that may affect proliferation was taken into account. In addition, the percentage of cells in S-phase normalised to cells treated with $17 \beta$-estradiol to allow for direct comparison to the proliferation levels achieved by FRs to those of $17 \beta$-estradiol. Statistical significance was established using oneway ANOVA followed by Dunnett's test for comparison to control group (solvent control for estrogenicity assays, and $17 \beta$-estradiol for anti-estrogenicity assays). $\mathrm{EC}_{20}$ and $\mathrm{IC}_{20}$ values were obtained following best-fit regression curves determination. Direct comparison of $\mathrm{EC}_{20}$ and $\mathrm{IC}_{20}$ values between FR treatments and E2 were then made to determine (anti)estrogenic potential of FRs compared to control compounds. A similar approach has been taken in other studies (Vanparys et al., 2010). 


\section{Results}

\subsection{Estrogen-like potential of flame retardants}

All twelve FRs were tested using the flow cytometric cell proliferation at the highest concentrations listed in Table 1. At these concentrations, there were few to none cytotoxicity effects as measured by resazurin sodium salt cell-viability assays (S1 Table, Supplementary information). Given that the MCF-7 cell line is estrogen receptor $\alpha$ positive, and therefore responsive to estrogens, E2 was used as control. Five FRs (TPP, TDCPP, TnBP, HBCD, and TBBPA) showed statistically significant estrogenic activity (Fig. 1). However, some dose response curves seem to be non-monotonic, with proliferation decreasing at higher concentrations (Fig. 1B, 1C, 1E, 1F). Importantly, minimal cytotoxicity was observed at these high concentrations (S1 Table, Supplementary information). TCPP, TPP, TCEP, TnBP, and HBCD were able to significantly affect cell viability compared to control at test concentrations, the greatest decrease in cell viability being $25.5 \%$ for TnBP, indicating limited MCF7 cytotoxicity effects of these compounds even at such high test concentrations (S1 Table, Supplementary information). To assess possible compound precipitation that may explain the nonmonotonic dose-response graphs in Figure 1, compounds were measured by photospectometry for turbidity at concentrations listed in Table 1. All compounds exhibiting such profiles (i.e. TPP, TDCPP, HBCD, and TBBPA) indeed showed precipitation at higher concentrations, likely due to low solubility as indicated by high $\operatorname{LogK}_{\mathrm{ow}}$ values (Table 1), with HBCD showing the highest levels of precipitation and TPP the least (S1 Fig, Supplementary information). We therefore excluded these values from the curve fittings (Figure 1) and calculations of $\mathrm{EC}_{20}$ values. Similar responses were also observed in other studies investigating estrogenic activities, though none of which presented suitable conclusions as to why such responses occurred (Blair et al., 2000; Korner et al., 1998).

$\mathrm{E} 2$ achieved an $\mathrm{EC}_{20}$ value of $0.8 \mathrm{pM}$ (Table 1), and a sigmoidal curve with saturation at higher concentrations (Figure 1A). When normalised to E2, TPP achieved the highest levels of proliferation at $87.0 \%$ compared to $\mathrm{E} 2$ with an $\mathrm{EC}_{20}$ of $88.0 \mu \mathrm{M}(95 \% \mathrm{Cl} 65.7$ to $118.0 \mu \mathrm{M})$ (Table 2). TDCPP 
treatment achieved $33.4 \%$ proliferation with an $\mathrm{EC}_{20}$ of $20.6 \mu \mathrm{M}(95 \% \mathrm{Cl} 13.0$ to $32.7 \mu \mathrm{M})$. The brominated flame retardant HBCD achieved a proliferation level of $33.5 \%$ when compared to E2 and an $\mathrm{EC}_{20}$ of $5.5 \mu \mathrm{M}(95 \% \mathrm{Cl} 3.0$ to $10.2 \mu \mathrm{M})$. TBBPA achieved $69.5 \%$ proliferative capacity while having an $\mathrm{EC}_{20}$ value of $124.0 \mu \mathrm{M}(95 \% \mathrm{Cl} 94.2$ to $163.3 \mu \mathrm{M})$ (Table 2). TnBP achieved a proliferative effect of only $15.3 \%$ and therefore could not produce an $\mathrm{EC}_{20}$ value (Table 2 ).

Relative potencies of FRs to induce estrogenic effects were compared to the potency of E2. Relative proliferative potency (RPP) was only determined for compounds able to return an $\mathrm{EC}_{20}$ value (Table 2). TPP, TDCPP, HBCD, and TBBPA achieved RPP values of $9 \times 10^{-9}, 4 \times 10^{-8}, 1 \times 10^{-7}$, and $6 \times 10^{-9}$ respectively. This indicates that HBCD was the most potent followed by TDCPP, TPP, and finally by TBBPA. However, potencies were many orders of magnitude lower when compared to that of E2.

\subsection{Anti-estrogen potential of flame retardants}

All twelve FRs were tested using the flow cytometric cell proliferation at the highest concentrations listed in Table 1. Briefly, MCF-7 cells were co-treated with both FR compound and 100 pM E2, a concentration at which maximum proliferative effect of E2 is observed without saturation of the growth curve (Figure 1A). A dose-dependent decrease in cells in S-phase would therefore correspond to the anti-estrogenic activity of the FR compound. Once again, it should be noted that there were limited cytotoxic effects associated at these concentrations (S1 Table, Supplementary information). Decreases in proliferation of MCF-7 cells are therefore mainly the result of estrogen receptor/pathway antagonism rather than cytotoxicity. Seven FRs exhibited anti-estrogenic effects (Figure 2). Dose-responses were sigmoidal, with higher concentrations of compound inducing a greater effect. Data was normalised to percentage of cells in S-phase at 100 pM E2.

The ER antagonist, Faslodex (ICI 182,780), was used as a positive control (Figure 2A), achieving a relative inhibitory effect (RIE) of $117.0 \%$ when normalised to blank and $100 \mathrm{pM} E 2$, and an $\mathrm{IC}_{20}$ value of $0.9 \mathrm{nM}(95 \% \mathrm{Cl} 0.4$ to $1.7 \mathrm{nM})$ could be calculated (Table 3). Of note, the greater than $100 \%$ 
decrease in proliferation is as a result of cell numbers in S-phase being lower than blank control at high concentrations of Faslodex. When normalised to E2, TBEP achieved an inhibition of $86.7 \%$ in proliferation with an $\mathrm{IC}_{20}$ value of $215.4 \mu \mathrm{M}(95 \% \mathrm{Cl} 142.6$ to $325.3 \mu \mathrm{M})$ (Figure 2B, Table 3). TDCPP achieved $101.3 \%$ inhibition with an $\mathrm{IC}_{20}$ value of $38.0 \mu \mathrm{M}(95 \% \mathrm{Cl} 30.9$ to $46.9 \mu \mathrm{M})$ (Figure $2 \mathrm{C}$, Table 3). TCEP inhibited proliferation by $32.2 \%$ with an $\mathrm{IC}_{20}$ of $661.7 \mu \mathrm{M}(95 \% \mathrm{Cl} 539.9$ to $810.9 \mu \mathrm{M})$ (Figure 2D, Table 3). TnBP treatment resulted in a $100.7 \%$ decrease in proliferation and an $\mathrm{IC}_{20}$ value of $183.6 \mu \mathrm{M}(95 \% \mathrm{Cl} 100.8$ to $334.3 \mu \mathrm{M})$ (Figure $2 \mathrm{E}$, Table 3). Of the brominated flame retardants, $\mathrm{HBCD}$ inhibited proliferation by $96.3 \%$ with an $\mathrm{IC}_{20}$ value of $17.6 \mu \mathrm{M}(95 \% \mathrm{Cl} 10.8$ to $28.7 \mu \mathrm{M})$ (Figure $2 \mathrm{~F}$, Table 3), while TBBPA resulted in a $75.7 \%$ decrease in proliferation along with an $\mathrm{IC}_{20}$ value of 451.2 $\mu \mathrm{M}(95 \% \mathrm{Cl} 363.5$ to $560.1 \mu \mathrm{M})$ (Figure $2 \mathrm{G}$, Table 3). TBC also indicated anti-estrogenic activity with a $22.9 \%$ decrease in proliferation and an $\mathrm{IC}_{20}$ concentration of $62.2 \mu \mathrm{M}(95 \% \mathrm{Cl} 40.7$ to $95.1 \mu \mathrm{M})$ (Figure $2 \mathrm{H}$, Table 3).

Relative potencies of FRs compared to Faslodex were determined where possible. Relative proliferative potency (RIP) was only determined for compounds able to return an $\mathrm{IC}_{20}$ value (Table 3 ). The majority of FRs possessed significant anti-estrogenic activity. TBEP, TDCPP, TCEP, TnBP, HBCD, TBBPA, and TBC achieved RIP values of $4 \times 10^{-6}, 2 \times 10^{-5}, 1 \times 10^{-6}, 5 \times 10^{-6}, 5 \times 10^{-5}, 2 \times 10^{-6}$, and $1 \times 10^{-5}$ respectively. This indicates that HBCD was the most potent followed by TDCPP, TBC, TnBP, TBEP, TBBPA, and finally TCEP. However, potencies were many orders of magnitude lower when compared to that of Faslodex. 


\section{Discussion}

FRs have been used for decades both for fire protection some and as plasticisers (Meeker and Stapleton, 2010), highlighting the omnipresence of FRs in today's world. Global demand for these compounds is, unsurprisingly, increasing on a yearly basis. Production volumes are notoriously difficult to obtain. However, as an indication of demand, the global demand for TBBPA is reported to have increased from 50000 tonnes per annum in 1992 to 145000 tonnes per year in 1998, with an average growth of $19 \%$ per year (EFSA, 2011), indicating the rapid increase in production and demand for FRs. Throughout the years, several compounds have been banned and/or phased out due to their persistence, bioaccumulation, and toxicity. The industry is therefore constantly adapting, with new compounds and mixtures being introduced regularly. The Registration, Evaluation, Authorization and Restriction of Chemicals (REACH) regulation was established in an effort to limit the use and production of potentially toxic chemicals within the European Union (EU). Registration of compounds for use within the EU involves conducting several toxicological studies. However, these studies are often limited to monitoring classical toxicological endpoints such as $L_{50}$ values, skin sensitization, carcinogenic potential, and immuno-, reproductive, and genotoxicity. There is therefore a clear lack of understanding of the potential mechanisms of endocrine-disruptive effects of these compounds, particularly for newer compounds such as PFRs and NBFRs (Mankidy et al., 2013; Meeker and Stapleton, 2010). This is particularly worrying since FRs are often persistent and bioaccumulative, whilst also showing a high level of atmospheric transport resulting in the contamination of distant environments (de Wit et al., 2010).

Given their persistence, potential bioaccumulation, and evidence of endocrine disruption in wildlife (Farhat et al., 2013; Patisaul et al., 2013; Wang et al., 2013), the present study evaluated potential estrogen-like and anti-estrogen like effects of twelve currently-used FRs using a MCF-7 flow cytometric proliferation assay. Proliferation of the estrogen receptor $\alpha$-positive human breast cancer cell line, MCF-7, has been routinely used as a measure of estrogenicity (Dorosh et al., 2010; Kojima 
et al., 2013; Olsen et al., 2003; Soto et al., 1995; Zhang et al., 2014). Interestingly, MCF-7 cells express necessary enzymes for the conversion of E2 by the aromatase pathway (CYP19A1) (Hevir et al., 2011; Wróbel and Gregoraszczuk, 2013) and are thus able to secrete E2 into media in response to estrogenic compounds (Wróbel and Gregoraszczuk, 2013). Additionally, MCF-7 cells are also able to downregulate bioaccessible E2 by expressing various phase I and phase II metabolising enzymes. Of the phase II enzymes, most important are sulfotransferases shown to bind to native E2 thereby decreasing bioavailable E2 (Adjei and Weinshilboum, 2002). Accordingly, other organic pollutants such as polychlorinated biphenyls have shown to exert their estrogenic activity by inhibiting these sulfotransferases rather than by binding to ER (Kester et al., 2002). Given that MCF-7 cells possess the ability to regulate E2, such an assay using MCF-7 cell proliferation is able to measure not only ERmediated estrogenic effects, but also non-receptor mediated effects. Given this, the Organisation for Economic Co-operation and Development (OECD) has recommended using such an assay when testing for estrogenicity (OECD, 2012). The MCF-7 flow-cytometric proliferation assay correlates well both qualitatively and quantitatively with other in vitro estrogen assays, is one of the most sensitive assays for detecting estrogenicity, while also decreasing the time required compared to the classical E-screen (Vanparys et al., 2010). Some of the disadvantages of the system includes the inability to establish whether estrogenic effects are receptor-mediated, and given the limited metabolic capacity of MCF-7 cells, only estrogenic effects of parent compound may be evaluated.

Both in vitro and in vivo observations suggest an estrogenic potential for FRs. Here, we observed that of the twelve compounds tested, five showed statistically significant estrogenic effects when compared to solvent control (Figure 1), with effects ranging from $15.3 \%$ to $87.0 \%$ proliferation when compared to E2 (Table 2). These compounds included TPP, TDCPP, TnBP, HBCD, and TBBPA. In contrast, TCPP, TBEP, TCEP, TEP, DOPO, TBPH, and TBC failed to induce any significant proliferation (S2 Fig, Supplementary information). 


\subsection{Brominated flame retardants}

Unfortunately, studies on the estrogenic activity of FRs in vitro are sometimes inconsistent, particularly for TBBPA. The estrogenic activity of TBBPA was investigated using various in vitro techniques. For instance, it was found that TBBPA had no effect on MCF-7 cell proliferation (Dorosh et al., 2010; Molina-Molina et al., 2013) or in other ER $\alpha$-positive human breast cancer cell lines (Meerts et al., 2001). While also showing an absence of binding to human ER (Hamers et al., 2006), these reports suggest that TBBPA exhibits no estrogenic activity. However, in accordance with our findings, other studies indicated that TBBPA treatment resulted in a pronounced increase in cell proliferation of MCF-7 cells (Korner et al., 1998; Olsen et al., 2003) accompanied by weak binding to human ER (Kitamura et al., 2005). Another study showed potential TBBPA estrogenicity without binding to human ER, suggesting a possible receptor-independent mechanism (Hamers et al., 2006). Table 4 below highlights the contradiction within the literature.

At first glance, it is apparent that the conflict is a result of highly differing concentrations used in the different studies. Taking this into account, the only two studies that are directly contradictory to each other are Molina-Molina et al., 2013 and Olsen et al., 2003 where the same concentration of TBBPA and assay was used. However, it should be noted that in the latter, TBBPA estrogenicity was limited (only $22 \%$ compared to $17 \beta$-estradiol). Taking this together with the findings that TBBPA may act as a potent sulfotransferase inhibitor (Hamers et al., 2006), our results together with previous studies suggest that the estrogenic activity of TBBPA may only be observed at high concentrations and that these responses are largely mediated by receptor-independent mechanisms.

The case of HBCD to potentially affect estrogenicity is less contentious. We here showed HBCD to elicit estrogenic effects, in line with other studies where HBCD was also observed to have an effect on MCF-7 cell proliferation (Dorosh et al., 2010). Interestingly, it was shown not to be an ER agonist (Hamers et al., 2006), suggesting that potential estrogenic effects of HBCD are not mediated by ER. 
Of the BFRs screened in this study, TBPH was another FR that has recently been investigated for estrogenic effects. It was found that TBPH treatments resulted in increased E2 production in the human adrenocarcinoma cell line, H295R, by effecting steroidogenesis (Mankidy et al., 2013; Saunders et al., 2013). However, we did not observe an effect on MCF-7 proliferation (S2 Fig, Supplementary information, Table 2), which was counter-intuitive given the ability for MCF-7 cells to produce E2 intrinsically as well (Wróbel and Gregoraszczuk, 2013). Additionally, to our knowledge, this is the first study to directly investigate potential estrogenic effects of TBC, of which none was observed using this assay (S2 Fig, Supplementary information, Table 2).

Here we showed that $H B C D$, TBBPA, and TBC decreased cell proliferation when co-treated with E2, thereby indicating potential anti-estrogenic effects (Figure 2F, 2G, and 2F, Table 3). HBCD has been shown to act as an ER antagonist whereas TBBPA does not (Hamers et al., 2006), indicating that HBCD exerts its anti-estrogenic effects likely through binding to ER while TBBPA acts by receptorindependent mechanisms. TBC only achieved a slight decrease in cellular proliferation (25.85\%) compared to control, indicating limited, albeit significant, anti-estrogenic activity. In our assay, TBPH failed to exhibit any statistically significant anti-estrogenic effects (S3 Fig, Supplementary information, Table 3) which does not agree with recent in vitro studies showing that TBPH possesses anti-estrogenic activity that is receptor-mediated (Fic et al., 2014; Saunders et al., 2013).

\subsection{Organophosphate flame retardants}

To our knowledge, there are very few studies assessing estrogenic effects of PFRs. TCPP, TPP, TBEP, TDCPP, and TCEP were shown to increase E2 concentrations in H295R cells (Liu et al., 2012), whereas our results suggest that TCPP, TBEP, and TCEP showed no signs of potential estrogenicity by affecting MCF-7 proliferation (S2 Fig, Supplementary information, Table 2), in contrast to TPP and TDCPP (Figure 1B \& 1C, Table 2). In other studies, it was observed that out of eleven PFRs tested, only TPP acted as an ER agonist (Kojima et al., 2013), while both TPP and TDCPP have been shown to increase E2 production (Liu et al., 2013b), to increase ER expression (Liu et al., 2013a), and to act as an ER 
agonist (Zhang et al., 2014). Taken together, while TPP, TDCPP, and TnBP were shown to exhibit estrogenic activity (Figure 1B, 1C, \& 1D, Table 2), it's likely that only TPP was able to act as an ER agonist while the others may be exerting their estrogenic effects by receptor-independent mechanisms.

To our knowledge, this is the first study investigating potential anti-estrogenic effects of TnBP, TEP, DOPO, and TBC. Additionally, provided that MCF-7 cells express phase I and phase II enzymes, they are able to downregulate bioavailable E2. Therefore, using this model to investigate potential antiestrogenic effects, receptor-dependent and -independent effects are taken into account.

Our results suggest that only TBEP, TDCPP, TCEP, and TnBP possess anti-estrogenic potential (Figure $2 \mathrm{~B}, 2 \mathrm{C}, 2 \mathrm{D}$, and 2E, Table 3). In agreement, a similar study involving the co-treatment of PFRs and E2 showed that TDCPP significantly reduced the binding affinity of E2 to ER in a concentrationdependent manner (Liu et al., 2012). However, TPP was shown to act in a similar manner, in disagreement with our results as TPP was observed not to harbour any anti-estrogenic effects (S3 Fig, Supplementary information, Table 3). In the same study (Liu et al., 2012), it was shown that TBEP did not possess any anti-estrogenic effects that were receptor-mediated, suggesting that the anti-estrogenic effects that we observed are receptor-independent (Figure 2B, Table 3). In agreement with previous studies, TCEP exhibited anti-estrogenic potential, which is likely to be receptor-mediated (Zhang et al., 2014).

\subsection{Potential mechanisms and relative potencies}

Notably in the present study, TDCPP, TnBP, HBCD, and TBBPA exhibit both estrogenic and antiestrogenic activity. Using MCF-7 cell proliferation as a model for observing potential endocrinedisrupting effects allowed for the investigation of both receptor-mediated and -independent mechanisms. This could explain as to how a compound may be estrogenic and anti-estrogenic in the same assay. A likely explanation for such contradicting activities is that FRs likely exert their 
estrogenic effects by altering bioavailable E2 levels, either by increasing E2 production (Liu et al., 2012, 2013b; Saunders et al., 2013), increasing ER expression (Liu et al., 2013a), or inhibiting E2 metabolism (Hamers et al., 2006). Anti-estrogenic activity can be mediated by both receptormediated, as observed in previous studies where co-treatment with E2 resulted in competitive binding to ER (Hamers et al., 2006; Liu et al., 2012), and receptor-independent mechanisms by altering E2 production, as some BFRs have previously been shown to inhibit aromatase (Cantón et al., 2005, 2008a). However, in this study, anti-estrogen activity is likely brought about by competitive binding to ER given that MCF-7 cells are treated at saturating levels of E2 and the short duration of the assay is unlikely to deplete such high levels of E2, thereby limiting possible effects of proliferation brought about by alterations to endogenous E2 production.

Relative potencies of FRs are many orders of magnitude lower than those of control compounds (E2 and Faslodex), indicating limited potential for FRs to affect estrogen function in this system. However, it should also be noted that this might not be the case in cell systems that are able to metabolise xenobiotics, since oxidative metabolism of some BFRs have been shown to potentiate their toxicity (Van Boxtel et al., 2008; Dingemans et al., 2008, 2011), and estrogenicity (Karpeta et al., 2014; Kojima et al., 2016). Additionally, risk assessment involves two aspects; hazard identification which concerns identifying health effects despite potential exposure levels, and exposure assessments which identify potential exposure levels likely to be encountered in a realworld setting. This study therefore involves hazard identification of FRs to illicit changes in estrogen function independent of concentrations that might be experienced in a practical setting. Perhaps most significant is that environmental levels of FRs have already been correlated to adverse health effects such as increased hormone levels (Johnson et al., 2013; Meeker and Stapleton, 2010) and a decline in semen quality (Meeker and Stapleton, 2010), indicating that despite their apparent low potential to illicit changes in estrogen function, adverse health effects arising from endocrine disruption attributed to FRs are observed, likely due to mixture toxicity and metabolite toxicity. 


\subsection{Correlation to in vivo data}

Limited studies investigating in vivo estrogenic effects of certain FRs exist. Initially, studies focussed on HBCD and TBBPA. However, in recent years, other FRs such as TPP, TDCPP, and other PFRs gained attention. Overall, findings from this study correlated well with other studies investigating the estrogenicity of these FRs in vivo, despite potential cross-species differences and differences in level of biological complexity. For instance, TBBPA exhibited estrogenic activity by increasing uterus weight in overiectomised mice (Kitamura et al., 2005), while also showing to increase aromatase activity in Wistar rats (Van der Ven et al., 2008). It should be noted that TBBPA failed to exhibit any estrogen-like effects in both chicken and quail embryos by means of monitoring Mullerian duct malformations and feminisation of testis (Berg et al., 2001). Also, TBBPA failed to induce any estrogen-like effects by measuring vitellogenin induction in rainbow trout (Christiansen et al., 2000). Comparison between bisphenol A, a known xenoestrogens, and synthetic estrogen diethylstilbestrol indicated that identification of estrogenic compounds and subsequent potency for potential xenoestrogens are both species and endpoint specific (Berg et al., 2001), thereby offering rationale for the conflicting reports investigating in vivo estrogenic potential of TBBPA when monitoring different endpoints in different species. HBCD has been shown to result in decreased weight of testis and correlated to increased activity of aromatase in Wistar rats (van der Ven et al., 2009), while also increasing estrogen metabolism in rats (Cantón et al., 2008b). Of the PFRs that showed estrogenic activity in our study, both TPP and TDCPP exhibited in vivo estrogenic effects by increasing plasma E2 levels in zebrafish which was also accompanied by an increase in aromatase and estrogen receptor expression (Liu et al., 2012, 2013b). Accordingly, estrogenic activity of TPP and TDCPP in humans was demonstrated by the positive association of these FRs to prolactin hormone levels in serum and thus a decrease in sperm quality (Meeker and Stapleton, 2010), given the link between estrogen activity and prolactin levels (Ismail et al., 1998). However, our results do not agree with other TBEP studies that have shown TBEP to modulate the estrogen receptor pathway in zebrafish by up-regulating estrogen receptor expression (Ma et al., 2015). 


\subsection{Shortcomings and position of in vitro assays in modern toxicology}

Several shortcomings of this study should be noted in the scope of risk assessment for potential endocrine disruptors. While this study may conclusively show estrogen-disruptive activity of several FRs, it should be highlighted that it might only applicable to in vitro models. These findings should therefore not be blindly extrapolated to in vivo models for potential estrogen-disruption of these FRs. In addition, given the simplicity of the in vitro model, only effects of parent compounds and not potential metabolites may be studied. Taken together, such in vitro studies should not be taken as any measure of true risk assessment. However, this is not to say that in vitro assays hold no place in modern toxicology. Such assays are valuable in studying potential mechanisms of toxicity that may give rise to adverse health effects seen in in vivo models. Unsurprisingly, such mechanistic insights have already been used to develop an adverse-outcome pathway regarding the ability for TBBPA to induce uterine tumours in rats (Wikoff et al., 2016). In this study, the potential of FRs to disrupt estrogen function that may give rise to the adverse health effects seen in vivo was investigated. These results correlated well to other studies investigating estrogen disruption in vivo as describe previously, further highlighting the applicability of such in vitro assays in a "weight-of-evidence" approach used to prioritise hazardous FRs for further study (Behl et al., 2015; Colnot et al., 2014). Additionally, in vitro-in vivo extrapolation (IVIVE) using physiologically based pharmacokinetic (PBPK) modelling have previously been used successfully to extrapolate in vitro findings to in vivo models but are limited to predicting toxicokinetics rather than adverse health effect (Chen et al., 2012; Jamei et al., 2014). Nevertheless, such information could be used to for predicting in vivo adverse health effects and therefore risk assessment (Rouquie et al., 2015), further emphasising the potential of in vitro assays to predict In vivo adverse health effects. Such an approach was not attempted in this study given that the parameters for successful PBPK incorporation, namely; absorption, metabolism, and excretion (Espié et al., 2009; Verner et al., 2011) are largely unknown for FRs (Hakk and Letcher, 2003). Only recently have studies been conducted to investigate human metabolization of FRs, particularly concerning PFRs (Van den Eede et al., 2013, 2015). 
Given the applicability of in vitro assays in toxicology, several institutions and agencies have been tasked with the mission to shift toxicological screening assays from in vivo to in vitro models in an effort to limit animal use and increase efficiency. For instance, the European Union Reference Laboratory for alternative methods to animal testing was established in 2011 to validate and replace current in vivo systems. Also, the US Environmental Protection Agency started the Tox21 initiative to identify mechanisms of chemically-induced biological activity to prioritise chemicals for more extensive toxicological evaluation. This is finally echoed by the Organisation for Economic Cooperation and Development Directorate involved in the assessment of endocrine disruptors as; "Positive in vitro test results indicate potential endocrine disruption activity and a potential for endocrine disruption effects in vivo. In vitro data can provide valuable mechanistic data that is useful for the design of further in vivo studies" (OECD, 2012). 


\section{Conclusion}

The MCF-7 flow cytometric proliferation assay allows for the rapid screening of compounds and account for both receptor-dependent and -independent activities. Of the twelve currently-used FRs screened in this study, eight exhibited disruption of the estrogen pathway, with five compounds exhibited statistically significant estrogenic activity (TPP, TDCPP, TnBP, HBCD, and TBBPA), and seven compounds harboured anti-estrogenic activity (TBEP, TDCPP, TCEP, TnBP, HBCD, TBBPA, and TBC). TDCPP, TnBP, HBCD, and TBBPA possess both estrogenic and anti-estrogenic activity. FRs therefore likely exert their estrogenic effects by altering bioaccessible E2 levels (Hamers et al., 2006; Liu et al., 2012, 2013b; Saunders et al., 2013), or by increasing ER expression (Liu et al., 2013a). Antiestrogenic activity could be both receptor-mediated, as evidenced by competitive binding of FRs to ER when co-treated with E2 (Hamers et al., 2006; Liu et al., 2012), and receptor-independent since BFRs have been shown to inhibit the aromatase enzyme (Cantón et al., 2005, 2008a). Relative potencies of FRs to control compounds were many orders of magnitude lower. However, environmental levels of FRs have already been correlated to adverse health effects, namely increased hormone levels (Johnson et al., 2013; Meeker and Stapleton, 2010) and a decline in semen quality (Meeker and Stapleton, 2010). The estrogenicity data generated here correlated well with other in vivo studies, highlighting the applicable use of in vitro models in determining potential adverse health effects. These findings therefore indicate potential estrogen-disruptive activities of several currently-used FRs.

\section{Acknowledgements}

This study was performed within the framework of a Marie Curie Initial Training Network (INFLAME, grant agreement 264600 ), funded by the $7^{\text {th }}$ EU Framework Programme. Research was funded by a Ph.D grant of the Agency for Innovation by Science and Technology (IWT) to BVK. Femke De Crooke and Maximilian Behr are acknowledged for help with the MCF-7 flow-cytometric proliferation assay. 


\section{References}

Abdallah, M.A., and Harrad, S. (2009). Personal exposure to HBCDs and its degradation products via ingestion of indoor dust. Environ. Int. 35, 870-876.

Abdallah, M.A., and Harrad, S. (2011). Tetrabromobisphenol-A , hexabromocyclododecane and its degradation products in UK human milk : Relationship to external exposure. Environ. Int. 37, 443448.

Adjei, A.A., and Weinshilboum, R.M. (2002). Catecholestrogen sulfation: possible role in carcinogenesis. Biochem. Biophys. Res. Commun. 292, 402-408.

Ali, N., Harrad, S., Goosey, E., Neels, H., and Covaci, A. (2011). "' Novel '" brominated flame retardants in Belgian and UK indoor dust : Implications for human exposure. Chemosphere 83, 1360-1365.

Behl, M., Hsieh, J.-H., Shafer, T.J., Mundy, W.R., Rice, J.R., Boyd, W.A., Freedman, J.H., Hunter, E.S., Jarema, K., Padilla, S., et al. (2015). Use of alternative assays to identify and prioritize organophosphorus flame retardants for potential developmental and neurotoxicity. Neurotoxicol. Teratol.

Berg, C., Halldin, K., and Brunstrom, B. (2001). Effects of bisphenol A and tetrabromobisphenol A on sex organ development in quail and chicken embryos. Environ. Toxicol. Chem. 20, 2836-2840.

Bergman, A., Heindel, J.J., Kasten, T., Kidd, K. a, Jobling, S., Neira, M., Zoeller, R.T., Becher, G., Bjerregaard, P., Bornman, R., et al. (2013). The impact of endocrine disruption: a consensus statement on the state of the science. Environ. Health Perspect. 121, A104-A106.

Birnbaum, L.S., and Staskal, D.F. (2004). Brominated Flame Retardants : Cause for Concern ? Environ. Health Perspect. 112, 9-17.

Blair, R.M., Fang, H., Branham, W.S., Hass, B.S., Dial, S.L., Moland, C.L., Tong, W., Shi, L., Perkins, R., and Sheehan, D.M. (2000). The estrogen receptor relative binding affinities of 188 natural and xenochemicals: structural diversity of ligands. Toxicol. Sci. 54, 138-153.

Blum, A., Gold, M., Ames, B., Jones, F., Hett, E., Dougherty, R., Horning, E., Dzidic, I., Carroll, D., Stillwell, R., et al. (1978). Children absorb tris-BP flame retardant from sleepwear: urine contains the mutagenic metabolite, 2,3-dibromopropanol. Science (80-. ). 201, 1020-1023.

Van Boxtel, A.L., Kamstra, J.H., Cenijn, P.H., Pieterse, B., Wagner, M.J., Antink, M., Krab, K., Van Der Burg, B., Marsh, G., Brouwer, A., et al. (2008). Microarray analysis reveals a mechanism of phenolic polybrominated diphenylether toxicity in zebrafish. Environ. Sci. Technol. 42, 1773-1779.

Cantón, R.F., Sanderson, J.T., Letcher, R.J., Bergman, A., and van den Berg, M. (2005). Inhibition and induction of aromatase (CYP19) activity by brominated flame retardants in H295R human adrenocortical carcinoma cells. Toxicol. Sci. 88, 447-455.

Cantón, R.F., Scholten, D.E. a, Marsh, G., de Jong, P.C., and van den Berg, M. (2008a). Inhibition of human placental aromatase activity by hydroxylated polybrominated diphenyl ethers (OH-PBDEs). Toxicol. Appl. Pharmacol. 227, 68-75.

Cantón, R.F., Peijnenburg, a. a C.M., Hoogenboom, R.L. a P., Piersma, A.H., van der Ven, L.T.M., van den Berg, M., and Heneweer, M. (2008b). Subacute effects of hexabromocyclododecane (HBCD) on hepatic gene expression profiles in rats. Toxicol. Appl. Pharmacol. 231, 267-272.

Cao, Z., West, C., Norton-Wenzel, C.S., Rej, R., Davis, F.B., Davis, P.J., and Rej, R. (2009). Effects of resin or charcoal treatment on fetal bovine serum and bovine calf serum. Endocr. Res. 34, 101-108. 
Casas, E., Bonilla, E., Ducolomb, Y., and Betancourt, M. (2010). Differential effects of herbicides atrazine and fenoxaprop-ethyl, and insecticides diazinon and malathion, on viability and maturation of porcine oocytes in vitro. Toxicol. Vitr. 24, 224-230.

Chen, Y., Jin, J., Mukadam, S., Malhi, V., and Kenny, J. (2012). Application of IVIVE and PBPK modeling in prospective prediction of clinical pharmacokinetics: strategy and approach during the drug discovery phase with four case studies. Biopharm. Drug Dispos. 33, 85-89.

Christiansen, L., Pedersen, K., Pedersen, S., Korsgaard, B., and Bjerregaard, P. (2000). In vivo comparison of xenoestrogens using rainbow trout vitollogenin induction as a screening system. Environ. Toxicol. Chem. 19, 1867-1874.

Colnot, T., Kacew, S., and Dekant, W. (2014). Mammalian toxicology and human exposures to the flame retardant 2,2',6,6'-tetrabromo-4,4'-isopropylidenediphenol (TBBPA): implications for risk assessment. Arch. Toxicol. 88, 553-573.

Covaci, A., Gerecke, A.C., Law, R.J., Voorspoels, S., Kohler, M., Heeb, N. V, Leslie, H., Allchin, C.R., and Boer, J.D.E. (2006). Critical Review Hexabromocyclododecanes ( HBCDs ) in the Environment and Humans : A Review. Environ. Sci. Technol. 40, 3679-3688.

Covaci, A., Harrad, S., Abdallah, M.A., Ali, N., Law, R.J., Herzke, D., and Wit, C.A. De (2011). Novel brominated flame retardants : A review of their analysis, environmental fate and behaviour. Environ. Int. 37, 532-556.

Diamanti-Kandarakis, E., Bourguignon, J.-P., Giudice, L.C., Hauser, R., Prins, G.S., Soto, A.M., Zoeller, R.T., and Gore, A.C. (2009). Endocrine-disrupting chemicals: an Endocrine Society scientific statement. Endocr. Rev. 30, 293-342.

Dingemans, M.M.L., de Groot, A., van Kleef, R.G.D.M., Bergman, Å., van den Berg, M., Vijverberg, H.P.M., and Westerink, R.H.S. (2008). Hydroxylation increases the neurotoxic potential of BDE-47 to affect exocytosis and calcium homeostasis in PC12 cells. Environ. Health Perspect. 116, 637-643.

Dingemans, M.M.L., van den Berg, M., and Westerink, R.H.S. (2011). Neurotoxicity of brominated flame retardants: (In)direct effects of parent and hydroxylated polybrominated diphenyl ethers on the (Developing) nervous system. Environ. Health Perspect. 119, 900-907.

Dodson, R.E., Perovich, L.J., Covaci, A., Van den Eede, N., lonas, A.C., Dirtu, A.C., Brody, J.G., and Rudel, R. a (2012). After the PBDE phase-out: a broad suite of flame retardants in repeat house dust samples from California. Environ. Sci. Technol. 46, 13056-13066.

Dorosh, A., Ded, L., Elzeinova, F., and Peknicova, J. (2010). Assessing Oestrogenic Effects of Brominated Flame Retardants Hexabromocyclododecane and Tetrabromobisphenol A on MCF-7 Cells. Folia Biol. (Praha). 39, 35-39.

Van den Eede, N., Maho, W., Erratico, C., Neels, H., and Covaci, A. (2013). First insights in the metabolism of phosphate flame retardants and plasticizers using human liver fractions. Toxicol. Lett. 223, 9-15.

Van den Eede, N., Erratico, C., Exarchou, V., Maho, W., Neels, H., and Covaci, A. (2015). In vitro biotransformation of tris ( 2-butoxyethyl) phosphate ( TBOEP) in human liver and serum. Toxicol. Appl. Pharmacol. 284, 246-253.

EFSA (2011). Scientific Opinion on Tetrabromobisphenol A ( TBBPA ) and its derivatives.

Ema, M., Fujii, S., Hirata-Koizumi, M., and Matsumoto, M. (2008). Two-generation reproductive toxicity study of the flame retardant hexabromocyclododecane in rats. Reprod. Toxicol. 25, 335-351.

Espié, P., Tytgat, D., Sargentini-Maier, M.-L., Poggesi, I., and Watelet, J.-B. (2009). Physiologically based pharmacokinetics (PBPK). Drug Metab. Rev. 41, 391-407. 
Farhat, A., Crump, D., Chiu, S., Williams, K.L., Letcher, R.J., Gauthier, L.T., and Kennedy, S.W. (2013). In Ovo effects of two organophosphate flame retardants--TCPP and TDCPP--on pipping success, development, mRNA expression, and thyroid hormone levels in chicken embryos. Toxicol. Sci. 134, 92-102.

Fic, A., Žegura, B., Gramec, D., and Mašič, L.P. (2014). Estrogenic and androgenic activities of TBBA and TBMEPH, metabolites of novel brominated flame retardants, and selected bisphenols, using the XenoScreen XL YES/YAS assay. Chemosphere 112, 362-369.

Guo, Y.L., Yu, M.L., Hsu, C.C., and Rogan, W.J. (1999). Chloracne, goiter, arthritis, and anemia after polychlorinated biphenyl poisoning: 14-Year follow-up of the Taiwan Yucheng cohort. Environ. Health Perspect. 107, 715-719.

Hakk, H., and Letcher, R.J. (2003). Metabolism in the toxicokinetics and fate of brominated flame retardants--a review. Environ. Int. 29, 801-828.

Hamers, T., Kamstra, J.H., Sonneveld, E., Murk, A.J., Kester, M.H. a, Andersson, P.L., Legler, J., and Brouwer, A. (2006). In vitro profiling of the endocrine-disrupting potency of brominated flame retardants. Toxicol. Sci. 92, 157-173.

Harrad, S., de Wit, C.A., Abdallah, M.A., Bergh, C., Björklund, J.A., Covaci, A., Darnerud, P.O., de Boer, J., Diamond, M., Huber, S., et al. (2010). Indoor contamination with hexabromocyclododecanes, polybrominated diphenyl ethers, and perfluoroalkyl compounds: an important exposure pathway for people? Environ. Sci. Technol. 44, 3221-3231.

Hayes, T.B., Collins, A., Lee, M., Mendoza, M., Noriega, N., Stuart, A.A., and Vonk, A. (2002). Hermaphroditic, demasculinized frogs after exposure to the herbicide atrazine at low ecologically relevant doses. Proc. Natl. Acad. Sci. U. S. A. 99, 5476-5480.

Hevir, N., Trošt, N., Debeljak, N., and Rižner, T.L. (2011). Expression of estrogen and progesterone receptors and estrogen metabolizing enzymes in different breast cancer cell lines. Chem. Biol. Interact. 191, 206-216.

Ismail, M., Serour, G., Torsten, U., Weitzel, H., and Berlien, H.P. (1998). Elevated serum prolactin level with high-dose estrogen contraceptive pills. Eur. J. Contracept. Reprod. Heal. Care 3, 45-50.

Jamei, M., Bajot, F., Neuhoff, S., Barter, Z., Yang, J., Rostami-Hodjegan, A., and Rowland-Yeo, K. (2014). A mechanistic framework for in vitro-in vivo extrapolation of liver membrane transporters: Prediction of drug-drug interaction between rosuvastatin and cyclosporine. Clin. Pharmacokinet. 53, 73-87.

Johnson, P.I., Stapleton, H.M., Mukherjee, B., Hauser, R., and Meeker, J.D. (2013). Associations between brominated flame retardants in house dust and hormone levels in men. Sci. Total Environ. 445-446, 177-184.

Karpeta, A., Ptak, A., and Gregoraszczuk, E.Ł. (2014). Different action of 2,2',4,4'-tetrabromodiphenyl ether (BDE-47) and its hydroxylated metabolites on ER $\alpha$ and $E R \beta$ gene and protein expression. Toxicol. Lett. 229, 250-256.

Kester, M.H.A., Bulduk, S., van Toor, H., Tibboel, D., Meinl, W., Glatt, H., Falany, C.N., Coughtrie, M.W.H., Schuur, A.G., Brouwer, A., et al. (2002). Potent inhibition of estrogen sulfotransferase by hydroxylated metabolites of polyhalogenated aromatic hydrocarbons reveals alternative mechanism for estrogenic activity of endocrine disrupters. J. Clin. Endocrinol. Metab. 87, 1142-1150.

Kitamura, S., Suzuki, T., Sanoh, S., Kohta, R., Jinno, N., Sugihara, K., Yoshihara, S., Fujimoto, N., Watanabe, H., and Ohta, S. (2005). Comparative study of the endocrine-disrupting activity of bisphenol A and 19 related compounds. Toxicol. Sci. 84, 249-259. 
Kojima, H., Takeuchi, S., Itoh, T., lida, M., Kobayashi, S., and Yoshida, T. (2013). In vitro endocrine disruption potential of organophosphate flame retardants via human nuclear receptors. Toxicology 314, 76-83.

Kojima, H., Takeuchi, S., Van den Eede, N., and Covaci, A. (2016). Effects of primary metabolites of organophosphate flame retardants on transcriptional activity via human nuclear receptors. Toxicol. Lett. 245, 31-39.

Korner, W., Hanf, V., Schuller, W., Bartsch, H., Zwirner, M., and Hanspaul, H. (1998). Validation and application of a rapid in vitro assay for assessing the estrogenic ptoency of halogenated phnolic chemicals. Chemosphere 31, 2395-2407.

Law, R.J., Herzke, D., Harrad, S., Morris, S., Bersuder, P., and Allchin, C.R. (2008). Levels and trends of $H B C D$ and BDEs in the European and Asian environments, with some information for other BFRs. Chemosphere 73, 223-241.

Lignell, S., Aune, M., Ola, P., Cnattingius, S., and Glynn, A. (2009). Persistent organochlorine and organobromine compounds in mother' s milk from Sweden 1996-2006 : Compound-specific temporal trends. Environ. Res. 109, 760-767.

Liu, C., Wang, Q., Liang, K., Liu, J., Zhou, B., Zhang, X., Liu, H., Giesy, J.P., and Yu, H. (2013a). Effects of tris ( 1, 3-dichloro-2-propyl) phosphate and triphenyl phosphate on receptor-associated mRNA expression in zebrafish embryos / larvae. Aquat. Toxicol. 128-129, 147-157.

Liu, X., Ji, K., and Choi, K. (2012). Endocrine disruption potentials of organophosphate flame retardants and related mechanisms in H295R and MVLN cell lines and in zebrafish. Aquat. Toxicol. 114-115, 173-181.

Liu, X., Ji, K., Jo, A., Moon, H.-B., and Choi, K. (2013b). Effects of TDCPP or TPP on gene transcriptions and hormones of HPG axis, and their consequences on reproduction in adult zebrafish (Danio rerio). Aquat. Toxicol. 134-135, 104-111.

Ma, Z., Yu, Y., Tang, S., Liu, H., Su, G., Xie, Y., Giesy, J.P., Hecker, M., and Yu, H. (2015). Differential modulation of expression of nuclear receptor mediated genes by tris (2-butoxyethyl) phosphate (TBOEP) on early life stages of zebrafish ( Danio rerio). Aquat. Toxicol. 169, 196-203.

Maffini, M. V, Rubin, B.S., Sonnenschein, C., and Soto, A.M. (2006). Endocrine disruptors and reproductive health: the case of bisphenol-A. Mol. Cell. Endocrinol. 254-255, 179-186.

Mankidy, R., Ranjan, B., Honaramooz, A., and Giesy, J.P. (2013). Effects of Novel Brominated Flame Retardants on Steroidogenesis in Primary Porcine Testicular Cells. Toxicol. Lett. 224, 141-146.

Maravilla-Galvan, R., Fierro, R., Gonzalez-Marquez, H., Gomez-Arryoyo, S., Jimenez, I., and Betancourt, M. (2009). Effects of atrazine and fenoxaprop-ethyl on capacitation and the acrosomal reaction in boar sperm. Int. J. Toxicol. 28, 24-32.

Meeker, J.D., and Stapleton, H.M. (2010). House Dust Concentrations of Organophosphate Flame Retardants in Relation to Hormone Levels and Semen Quality Parameters. Environ. Health Perspect. $118,318-324$.

Meerts, I.A.T.M., Letcher, R.J., Hoving, S., Marsh, G., Bergman, A., Lemmen, J.G., van der Burg, B., and Brouwer, A. (2001). In vitro estrogenicity of polybrominated diphenyl ethers, hydroxylated PDBEs, and polybrominated bisphenol A compounds. Environ. Health Perspect. 109, 399-407.

Molina-Molina, J.-M., Amaya, E., Grimaldi, M., Sáenz, J.-M., Real, M., Fernández, M.F., Balaguer, P., and Olea, N. (2013). In vitro study on the agonistic and antagonistic activities of bisphenol-S and other bisphenol-A congeners and derivatives via nuclear receptors. Toxicol. Appl. Pharmacol. 272, 127-136. 
Muñoz-de-Toro, M., Markey, C.M., Wadia, P.R., Luque, E.H., Rubin, B.S., Sonnenschein, C., and Soto, A.M. (2005). Perinatal exposure to bisphenol-A alters peripubertal mammary gland development in mice. Endocrinology 146, 4138-4147.

OECD (2012). OECD Conceptual Framework for Testing and Assessment of Endocrine Disrupters (as revised in 2012).

Olsen, C.M., Meussen-Elholm, E.T.M., Samuelsen, M., Holme, J.A., and Hongslo, J.K. (2003). Effects of the environmental oestrogens bisphenol $A$, tetrachlorobisphenol $A$, tetrabromobisphenol A, 4hydroxybiphenyl and 4,4'-dihydroxybiphenyl on oestrogen receptor binding, cell proliferation and regulation of oestrogen sensitive proteins in the human. Pharmacol. Toxicol. 92, 180-188.

Patisaul, H.B., Roberts, S.C., Mabrey, N., Mccaffrey, K.A., Gear, R.B., Braun, J., Belcher, S.M., and Stapleton, H.M. (2013). Accumulation and Endocrine Disrupting Effects of the Flame Retardant Mixture Firemaster 550 in Rats : An Exploratory Assessment. J. Biochem. Mol. Toxicol. 27, 124-136.

Petruševska, M., Urleb, U., and Peternel, L. (2013). Evaluation of the light scattering and the turbidity microtiter plate-based methods for the detection of the excipient-mediated drug precipitation inhibition. Eur. J. Pharm. Biopharm. 85, 1148-1156.

Preuss, T.G., Gehrhardt, J., Schirmer, K., Coors, A., Rubach, M., Russ, A., Jones, P.D., Giesy, J.P., and Ratte, H.T. (2006). Nonylphenol isomers differ in estrogenic activity. Environ. Sci. Technol. 40, 51475153.

Roberge, M., Hakk, H., and Larsen, G. (2004). Atrazine is a competitive inhibitor of phosphodiesterase but does not affect the estrogen receptor. Toxicol. Lett. 154, 61-68.

Rouquie, D., Heneweer, M., Botham, J., Ketelslegers, H., Markell, L., Pfister, T., Steiling, W., Strauss, V., and Hennes, C. (2015). Contribution of new technologies to characterization and prediction of adverse effects. Crit. Rev. Toxicol. 45, 172-183.

Salmeia, K.A., and Gaan, S. (2015). An overview of some recent advances in DOPO-derivatives: Chemistry and flame retardant applications. Polym. Degrad. Stab. 113, 119-134.

Saunders, D.M. V, Higley, E.B., Hecker, M., Mankidy, R., and Giesy, J.P. (2013). In vitro endocrine disruption and TCDD-like effects of three novel brominated flame retardants: TBPH, TBB, \& TBCO. Toxicol. Lett. 223, 252-259.

Sharpe, R.M., and Irvine, D.S. (2004). Clinical review: How strong is the evidence of a link between environmental chemicals and adverse effects on human reproductive health? Br. Med. J. 328, 447451.

Sharpe, R.M., and Skakkebæk, N.E. (1993). Are oestrogens involved in falling sperm counts and disorders of the male reproductive tract? Lancet 341, 1392-1396.

Soto, A.M., Sonnenschein, C., Chung, K.L., Mariana, F., Olea, N., and Serrano, F.O. (1995). The Escreen assay as a tool to identify estrogens: an update on estrogenic environmental pollutants. Environ. Health Perspect. 103, 113-122.

Sumpter, J.P. (1995). Feminized responses in fish to environmental estrogens. Toxicol. Lett. 83, 737742.

Vanparys, C., Maras, M., Lenjou, M., Robbens, J., Van Bockstaele, D., Blust, R., and De Coen, W. (2006). Flow cytometric cell cycle analysis allows for rapid screening of estrogenicity in MCF-7 breast cancer cells. Toxicol. Vitr. 20, 1238-1248.

Vanparys, C., Depiereux, S., Nadzialek, S., Robbens, J., Blust, R., Kestemont, P., and Coen, W. De (2010). Performance of the flow cytometric E-screen assay in screening estrogenicity of pure compounds and environmental samples. Sci. Total Environ. 408, 4451-4460. 
van der Veen, I., and de Boer, J. (2012). Phosphorus flame retardants: Properties, production, environmental occurrence, toxicity and analysis. Chemosphere 88, 1119-1153.

Van der Ven, L.T.M., Van de Kuil, T., Verhoef, A., Verwer, C.M., Lilienthal, H., Leonards, P.E.G., Schauer, U.M.D., Cantón, R.F., Litens, S., De Jong, F.H., et al. (2008). Endocrine effects of tetrabromobisphenol-A (TBBPA) in Wistar rats as tested in a one-generation reproduction study and a subacute toxicity study. Toxicology $245,76-89$.

van der Ven, L.T.M., van de Kuil, T., Leonards, P.E.G., Slob, W., Lilienthal, H., Litens, S., Herlin, M., Håkansson, H., Cantón, R.F., van den Berg, M., et al. (2009). Endocrine effects of hexabromocyclododecane (HBCD) in a one-generation reproduction study in Wistar rats. Toxicol. Lett. 185, 51-62.

Verner, M.-A., Bouchard, M., Fritsche, E., Charbonneau, M., and Haddad, S. (2011). In vitro neurotoxicity data in human risk assessment of polybrominated diphenyl ethers (PBDEs): overview and perspectives. Toxicol. In Vitro 25, 1509-1515.

Waaijers, S.L., Bleyenberg, T.E., Dits, A., Schoorl, M., Schütt, J., Kools, S. a E., de Voogt, P., Admiraal, W., Parsons, J.R., and Kraak, M.H.S. (2013). Daphnid life cycle responses to new generation flame retardants. Environ. Sci. Technol. 47, 13798-13803.

Wang, Q., Liang, K., Liu, J., Yang, L., Guo, Y., Liu, C., and Zhou, B. (2013). Exposure of zebrafish embryos/larvae to TDCPP alters concentrations of thyroid hormones and transcriptions of genes involved in the hypothalamic-pituitary-thyroid axis. Aquat. Toxicol. 126, 207-213.

Wikoff, D.S., Rager, J.E., Haws, L.C., and Borghoff, S.J. (2016). A high dose mode of action for Tetrabromobisphenol A-induced uterine adenocarcinomas in Wistar Han rats: a critical evaluation of key events in an adverse outcome pathway framework. Regul. Toxicol. Pharmacol.

de Wit, C.A., Herzke, D., and Vorkamp, K. (2010). Brominated flame retardants in the Arctic environment--trends and new candidates. Sci. Total Environ. 408, 2885-2918.

Wróbel, A., and Gregoraszczuk, E.t. (2013). Effects of single and repeated in vitro exposure of three forms of parabens, methyl-, butyl- and propylparabens on the proliferation and estradiol secretion in MCF-7 and MCF-10A cells. Pharmacol. Rep. 65, 484-493.

Wu, Z., Tucker, I.G., Razzak, M., and Medlicott, N.J. (2005). An in vitro kinetic method for detection of precipitation of poorly soluble drugs. Int. J. Pharm. 304, 1-3.

Zhang, Q., Lu, M., Wang, C., Zhang, C., Liu, W., and Zhao, M. (2014). Potential Estrogenic Effects of Phosphorus-Containing Flame Retardants. Environ. Sci. Technol. 48, 6995-7001.

Zhu, N., Li, A., Wang, T., Wang, P., Qu, G., Ruan, T., Fu, J., Yuan, B., Zeng, L., Wang, Y., et al. (2012). Tris(2,3-dibromopropyl) isocyanurate, hexabromocyclododecanes, and polybrominated diphenyl ethers in mollusks from Chinese Bohai Sea. Environ. Sci. Technol. 46, 7174-7181. 
A

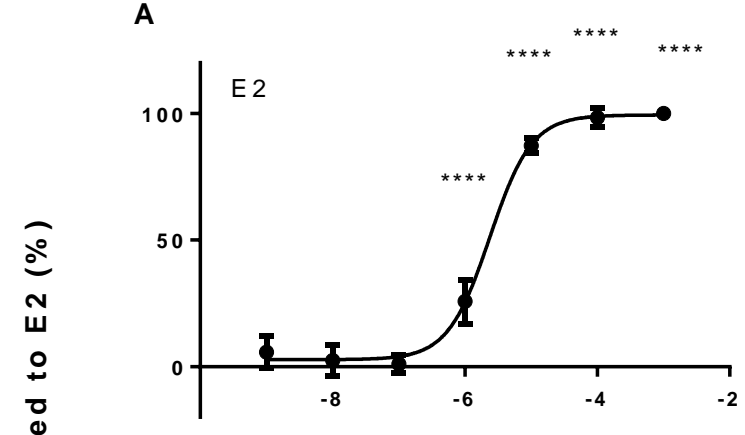

C

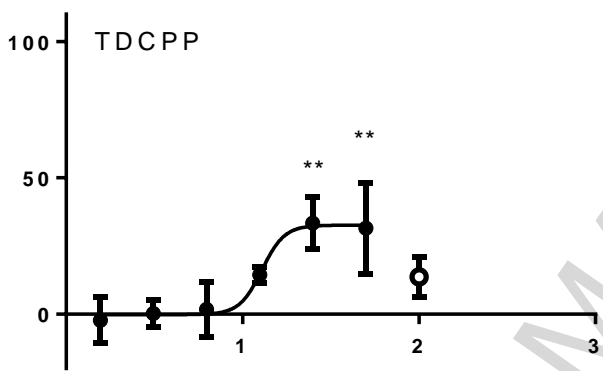

E

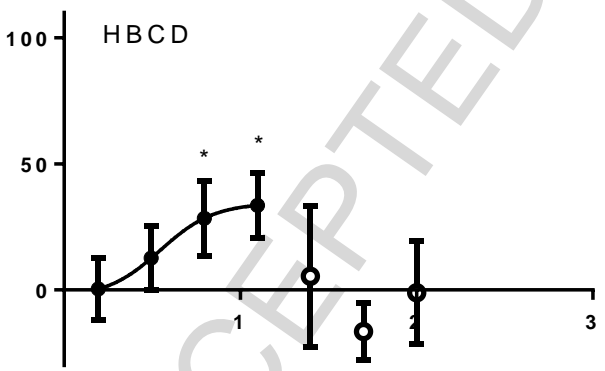

B

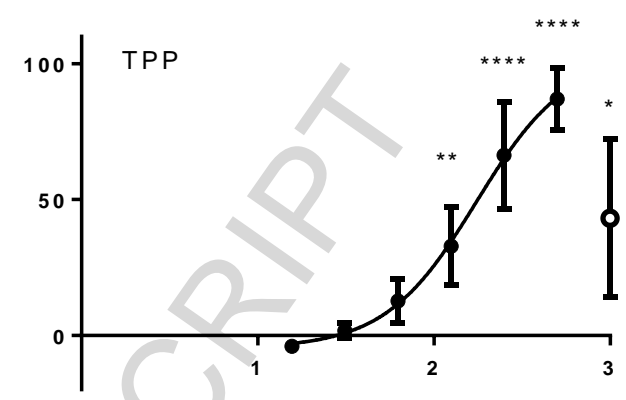

D

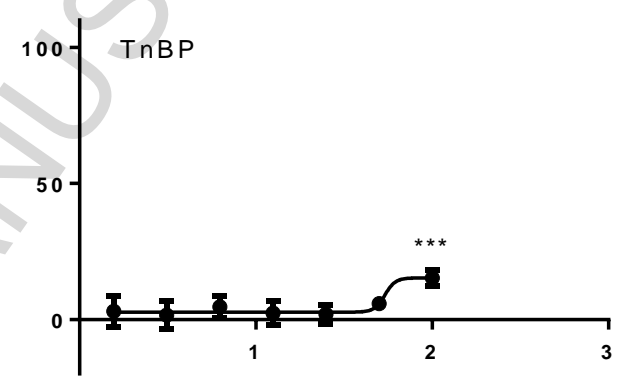

F

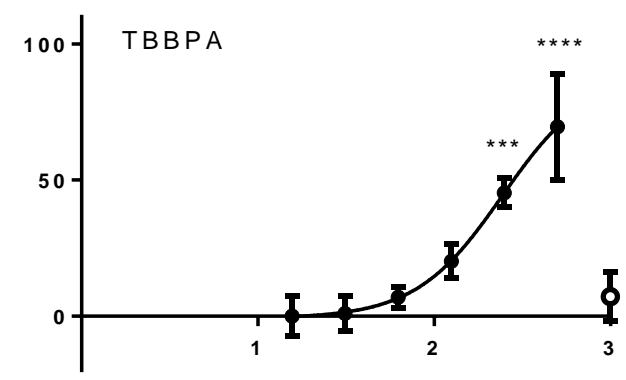

Concentration ( $\log M$ )

Figure 1. Proliferative effects of compounds on MCF-7 cells as a measure of estrogenic potential. Data presented as proliferation levels normalised to those achieved by control (E2). Results are an average of three independent replicates $(n=3)$. Bars indicate SD. Asterisks indicate significant differences from $0 \%$ (one-way ANOVA, Dunnett's test; * $p<0.05$ $\left.{ }^{* *} p<0.01 * * * p<0.001 * * * * p<0.0001\right) . \bullet-$ data points included for curve fitting, $\circ-$ data points excluded from curve fitting due to compound precipitation (A) E2, (B) TPP, (C) TDCPP, (D) TnBP, (E) HBCD, (F) TBBPA. 

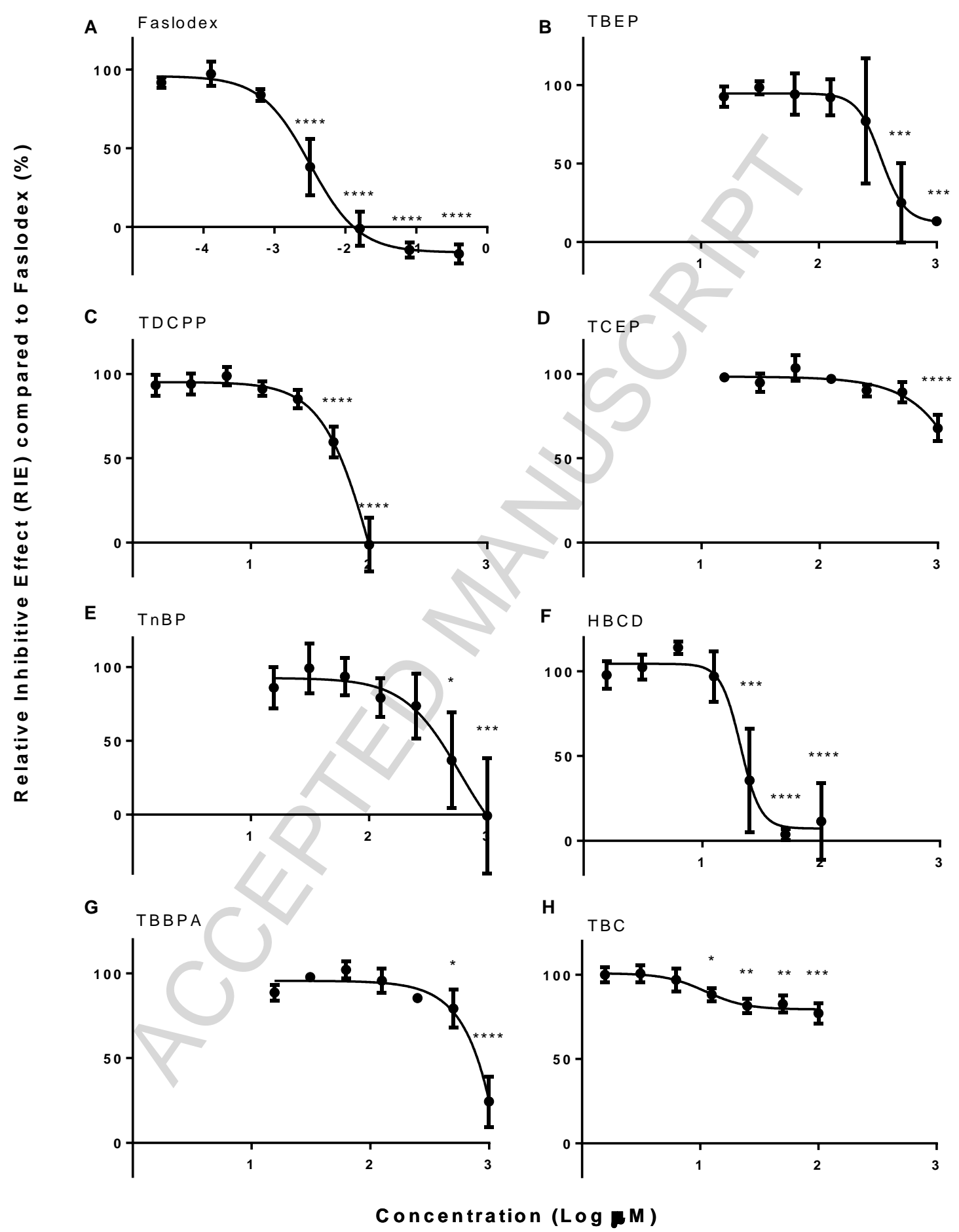

Figure 2. Anti-proliferative effects of compounds on MCF-7 cells as a measure of anti-estrogenic potential. Data presented as proliferation levels normalised to those achieved by control (Faslodex). Results are an average of three independent replicates $(n=3)$. Bars indicate SD. Asterisks indicate significant differences from 100\% (one-way ANOVA, Dunnett's test; ${ }^{*} \mathrm{p}<0.05 * * \mathrm{p}<0.01 * * * \mathrm{p}<0.001 * * * * \mathrm{p}<0.0001$ ). (A) Faslodex, (B) TBEP, (C) TDCPP, (D) TCEP, (E) TnBP, (F) HBCD, (G) TBBPA, (H) TBC. 
Table 1. All compounds with highest concentration tested, separated into their major classes of flame retardants

\begin{tabular}{|c|c|c|c|c|c|}
\hline Class & Chemical Name & Abbreviation & CAS Number & $\begin{array}{c}\text { Highest } \\
\text { concentration tested } \\
(\mu \mathrm{M})\end{array}$ & $\log _{\text {ow }}$ \\
\hline \multirow[t]{8}{*}{ PFR } & Tris (1-chloro-2-propyl) phosphate & TCPP & $13674-84-5$ & 100 & 2.59 \\
\hline & Triphenyl phosphate & TPP & $115-86-6$ & 1000 & 4.59 \\
\hline & Tris (2-butoxyethyl) phosphate & TBEP & $78-51-3$ & 1000 & 3.75 \\
\hline & Tris (1,3-dichloro-2-propyl) phosphate & TDCPP & $13674-87-8$ & 100 & 3.65 \\
\hline & Tri (2-chloroethyl)phosphate & TCEP & $115-96-8$ & 1000 & 1.44 \\
\hline & Tris (butyl) phosphate & TnBP & $126-73-8$ & 1000 & 4.00 \\
\hline & Triethyl phosphate & TEP & $78-40-0$ & 1000 & 0.80 \\
\hline & 9,10-dihydro-9-oxa-10-phosphaphenanthrene & DOPO & $35948-25-5$ & 1000 & 1.87 \\
\hline \multirow[t]{4}{*}{ BFR } & Hexabromocyclododecane & $\mathrm{HBCD}$ & $3194-55-6$ & 100 & 5.62 \\
\hline & Tetrabromobisphenol A & TBBPA & $79-94-7$ & 1000 & 5.90 \\
\hline & Bis (2-ethylhexyl) tetrabromophthalate & TBPH & $26040-51-7$ & 100 & 11.95 \\
\hline & Tris (2,3,-dibromopropyl) isocyanurate & TBC & $52434-90-9$ & 100 & 7.37 \\
\hline \multirow[t]{2}{*}{ Controls } & $17 \beta$-estradiol & E2 & $50-28-2$ & 0.001 & 4.01 \\
\hline & $\mathrm{ICl} 182,780$ & Faslodex & $129453-61-8$ & 0.4 & 9.09 \\
\hline
\end{tabular}


Table 2. Relative proliferative effect (RPE) as a measure of relative proliferative potency (RPP) compared to $\mathrm{E}_{2}$. $\mathrm{EC}_{20}$ values were calculated based on dose-response profiles in Figure 1 and represent the concentration at which $20 \%$ of the proliferative effect of the positive control (E2) was achieved. The RPE was a measure of the maximal proliferative effect relative to $\mathrm{E} 2$ expressed as a percentage. RPP was calculated as $\mathrm{EC}_{20} \mathrm{E2} / \mathrm{EC}_{20}$ compound. $\mathrm{EC}_{20}$ values could not be determined (ND) for a majority of compounds as $20 \%$ proliferation was not achieved

\begin{tabular}{llrrrr}
\hline Class & Compound & RPE $(\%)$ & EC20 $(\mu \mathrm{M})$ & p-value & \multicolumn{1}{c}{ RPP } \\
\hline Control & E2 & 100 & $8 . E-07$ & $<0.0001$ & 1 \\
PFR & TCPP & 4.8 & ND & 0.193 & \\
& TPP & 87.0 & 88.0 & $<0.0001$ & $9 \times 10^{-9}$ \\
& TBEP & -3.1 & ND & 1.000 & \\
& TDCPP & 33.4 & 20.6 & 0.003 & $4 \times 10^{-8}$ \\
& TCEP & 4.4 & ND & 0.410 & \\
& TnBP & 15.3 & ND & 0.001 & \\
& TEP & -1.8 & ND & 0.994 & \\
& DOPO & 0.7 & ND & 1.000 & \\
& HBCD & 33.5 & 5.5 & 0.019 & $1 \times 10^{-7}$ \\
& TBBPA & 69.5 & 124.0 & $<0.0001$ & $6 \times 10^{-9}$ \\
& TBPH & -7.5 & ND & 0.918 & \\
& TBC & -5.5 & ND & 0.992 & \\
\hline
\end{tabular}


Table 3. Relative inhibitive effect (RIE) as a measure of relative inhibitive potency (RIP) and therefore anti-estrogenicity normalised to $\mathrm{E} 2 . \mathrm{IC}_{20}$ values were calculated based on dose-response profiles in Figure 2 and represent the concentration at which $20 \%$ of the proliferative effect of the 100 pM E2 was lost. The RIE was a measure of the maximal anti-proliferative effect expressed as a percentage. RIP was calculated as $I C_{20}$ Faslodex $/ I C_{20}$ compound. $I C_{20}$ values could not be determined (ND) for some compounds as $20 \%$ inhibition was not achieved.

\begin{tabular}{llrrrr}
\hline Class & Compound & RIE $(\%)$ & IC20 $(\mu \mathrm{M})$ & p-value & \multicolumn{1}{c}{ RIP } \\
\hline Control & Faslodex & 117.0 & $9 . \mathrm{E}-04$ & $<0.0001$ & 1 \\
PFR & TCPP & 11.0 & ND & 0.0771 & \\
& TPP & 11.7 & ND & 0.4484 & \\
& TBEP & 86.7 & 215.4 & 0.0002 & $4 \times 10^{-6}$ \\
& TDCPP & 101.3 & 38.0 & $<0.0001$ & $2 \times 10^{-5}$ \\
& TCEP & 32.2 & 661.7 & $<0.0001$ & $1 \times 10^{-6}$ \\
& TnBP & 100.7 & 183.6 & 0.0003 & $5 \times 10^{-6}$ \\
& TEP & 9.2 & ND & 0.2889 & \\
BFR & DOPO & 5.6 & ND & 0.8685 & \\
& HBCD & 96.3 & 17.6 & $<0.0001$ & $5 \times 10^{-5}$ \\
& TBBPA & 75.7 & 451.2 & $<0.0001$ & $2 \times 10^{-6}$ \\
& TBPH & 10.7 & ND & 0.0554 & \\
& TBC & 22.9 & 62.2 & 0.0002 & $1 \times 10^{-5}$ \\
\hline
\end{tabular}


Table 4: Estrogenicity of TBBPA in six different studies

\begin{tabular}{|c|c|c|c|c|}
\hline Study & Conclusion & Assay & Specifics & $\begin{array}{l}\text { Concentration } \\
\text { Used }(\mu \mathrm{M})\end{array}$ \\
\hline Dorosh et al., 2010 & Not estrogenic & EScreen & Measurement of cell number by MTT assay & 20 \\
\hline Molina-Molina et al., 2013 & Not estrogenic & EScreen & Measurement of cell number by SRB assay & 10 \\
\hline Hamers et al., 2006 & Not estrogenic & $\begin{array}{l}\text { ER-luciferase } \\
\text { reporter }\end{array}$ & $\begin{array}{l}\text { Luciferase expression in response to } \\
\text { treatment }\end{array}$ & 12.5 \\
\hline Kitamura et al., 2005 & Estrogenic & $\begin{array}{l}\text { ER-luciferase } \\
\text { reporter }\end{array}$ & $\begin{array}{l}\text { Luciferase expression in response to } \\
\text { treatment }\end{array}$ & 100 \\
\hline Olsen at al., 2003 & Estrogenic & EScreen & $\begin{array}{l}\text { Measurement of cell number by DNA } \\
\text { staining }\end{array}$ & 10 \\
\hline Korner et al., 1998 & Estrogenic & EScreen & Measurement of cell number by MTT assay & 100 \\
\hline
\end{tabular}




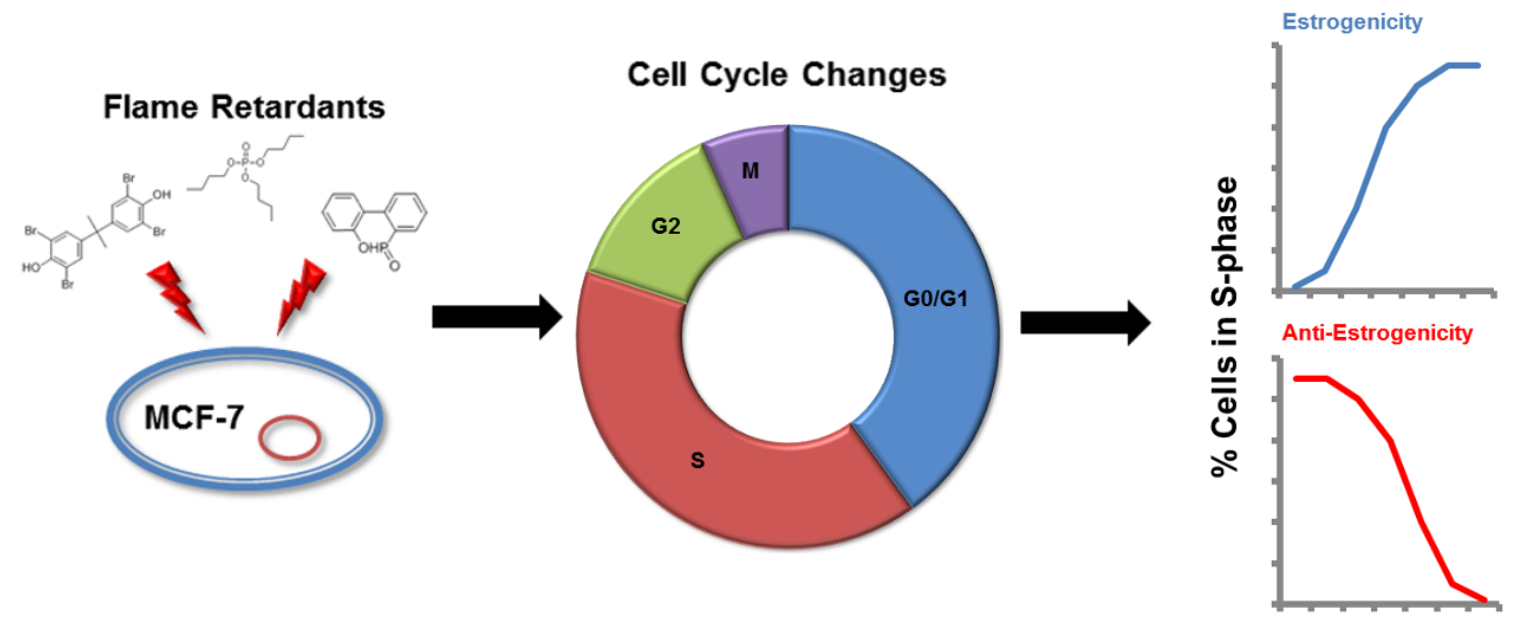

Graphical abstract 


\section{Highlights}

- Flame retardants are designed to prevent the initiation and spread of fire and increasing in use

- Increasing incidence of disorders attributed to endocrine disruption correlated to increase use of chemicals

- Estrogenicity and anti-estrogenicity of current flame retardants measured by MCF-7 flow-cytometric proliferation assay

- Majority of compounds altered estrogen function

- Estrogenicity and anti-estrogenicity likely mediated by receptor-independent and dependent mechanisms respectively 